\title{
The plasma kallikrein kinin system in severely ill and traumatised patients
}

\author{
A. D. CUMMING, C. E. ROBERTSON, S. S. JEFFREY, \\ J. S. ROBSON AND I. McA. LEDINGHAM \\ Medical Renal Unit, University Department of Medicine, Accident and Emergency \\ Department, Royal Infirmary, Edinburgh and Department of Surgery, Western Infirmary, \\ Glasgow
}

\section{SUMMARY}

Serial estimations of plasma prekallikrein in four critically ill patients in intensive care showed reduced values in each case, suggesting activation of the plasma kallikrein kinin system. In contrast, samples taken early from 15 patients attending an accident and emergency department with multiple trauma showed significantly elevated plasma prekallikrein concentrations; the significance of this observation is at present unclear.

\section{INTRODUCTION}

In 1905 Abelous described the preparation of an extract from human urine which when injected into dogs caused pronounced hypotension. The substances responsible for this effect were later isolated and given the name of kinins because of their ability to produce contraction of smooth muscle. There are two principal kinins, the nonapeptide bradykinin which predominates in plasma, and the decapeptide kallidin which is found primarily in urine (Levinsky, 1979). Kinins are very potent vasodilator substances, and bradykinin can prevent the vasoconstricting action of angiotensin II in equimolar concentrations. Kinins also increase capillary permeability and stimulate prostaglandin synthesis (Mills, 1979). Kinins are formed from inactive kininogen precursors by the action of kallikrein enzymes. There are two principal types of kallikrein. The plasma enzyme has a molecular weight around 100000 and normally circulates as an inactive precursor, prekallikrein. Other kallikrein enzymes, collectively known as glandular kallikreins, are found in various tissues including pancreas, submandibular glands, and the kidney. These have molecular weights around 40000 and have different substrate specificity from the plasma enzyme (Levinsky, 1979). The plasma kallikrein kinin system has important vasodilator and hypotensive effects and interacts with several 


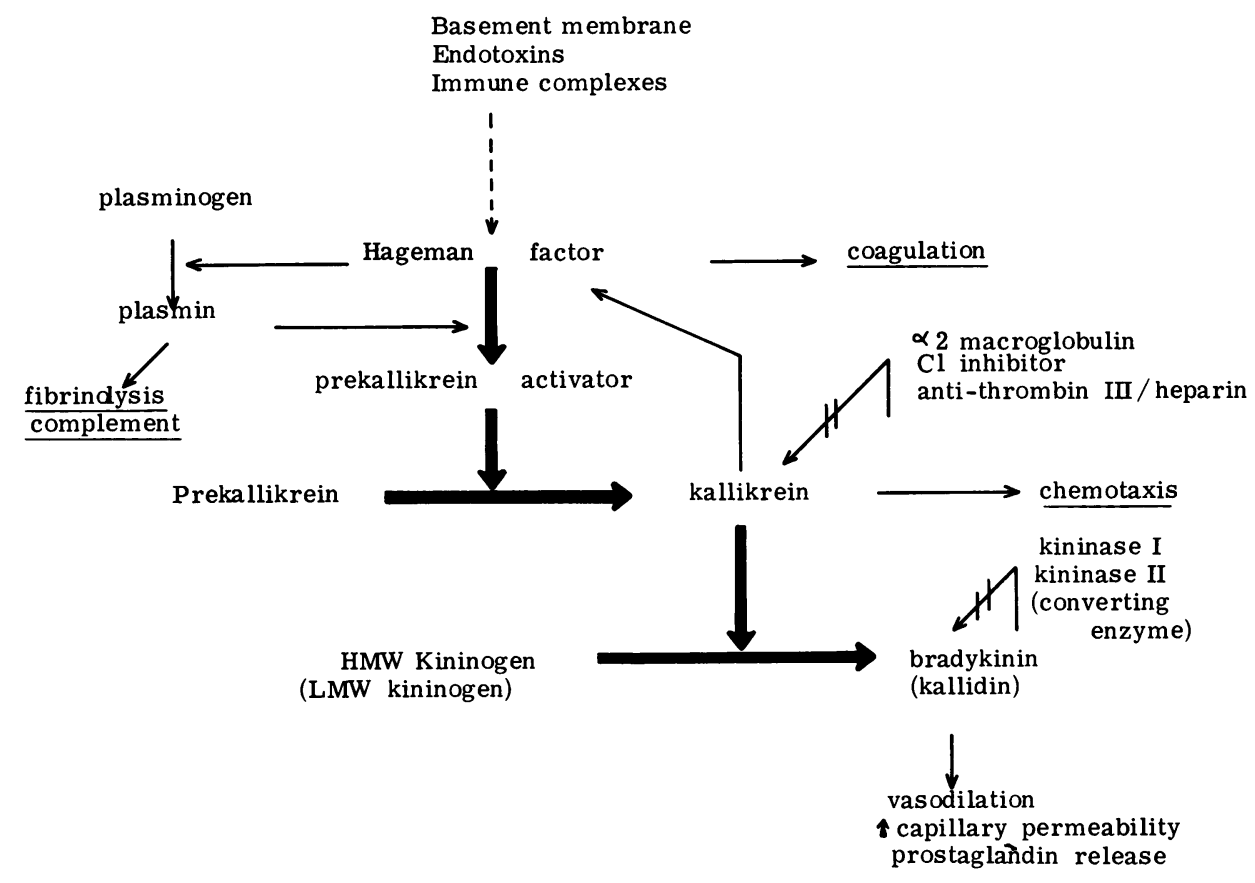

Fig. 1 The plasma kallikrein-kinin system.

other enzyme systems in blood (Kaplan et al., 1977) (Fig. 1). The two principal steps arre the conversion of prekallikrein to active kallikrein, which then acts on high molecular weight kininogen to form bradykinin. Active kallikrein is rapidly degraded in vivo ando has a half-life in the circulation of around $5 \mathrm{~min}$. The most important trigger of theo plasma kallikrein kinin system is activation of Factor XII (Hageman Factor). Activation $\overrightarrow{\overrightarrow{0}}$ of Factor XII also triggers both the coagulation pathway and the fibrinolytic pathway; plasmin then digests the active Factor XII to form various fragments collectively known as prekallikrein activator. These fragments then convert prekallikrein into plasma kallikrein; the active kallikrein feeds back up the pathway to stimulate directly further activation of Factor XII, thereby amplifying the response. Plasmin can also directly activate the classical complement sequence and a further link with complement is seen in the fact that the most important inhibitor of plasma kallikrein is $\mathrm{Cl}$ esterase inhibitor. $\ni$ Active kallikrein has been shown using the Boyden chamber to be chemotactic foro human neutrophils (Kaplan et al., 1971).

The activity of the plasma kallikrein kinin system can be assessed by various methods. Circulating bradykinin can be measured by bioassay or by radioimmunoassay. Activer plasma kallikrein can be measured either by enzymatic methods or by measuring the ability of plasma to liberate kinins from a known amount of kininogen precursor. Then biological half-life of bradykinin and kallikrein in plasma is short and these assays are technically difficult (Levinsky, 1979). An alternative approach is to convert all theo plasma prekallikrein to kallikrein in vitro then measure activity against a specifico substrate. A decrease in prekallikrein is taken to represent activation of the plasmakallikrein kinin system with consumption of precursors (Friberger et al., 1978). 
Bacterial endotoxins are known to be potent activators of the Factor XII dependent pathways (Kimball et al., 1972) and there is good experimental and clinical evidence that the plasma kallikrein kinin system is activated either by the injection of endotoxin (Neiss et al., 1968) or by Gram negative septicaemia (Webster et al., 1959; O'Donnell et al., 1976). Virtually all this work was done using either bioassays or enzymatic assays which measured total arginine esterase activity under alkaline conditions (Mason et al., 1970). Recently, synthetic tripeptide chromogenic substrate assays have become available, in which specificity is achieved by copying the amino acid sequence of the preferred substrate of a given enzyme (Friberger, 1978). We, therefore, attempted to discover if these previous observations could be confirmed at a clinical level using such a contemporary type of assay. Previous studies were based on single point in time measurements. We have therefore performed serial estimations of prekallikrein in criticially ill patients in an intensive care unit, some of whom had sepsis. Other substances known to activate Factor XII include collagen, vascular basement membrane, urate crystals and articular cartilage (Kaplan et al., 1977). We have therefore measured plasma prekallikrein in patients with multiple trauma who were not septic.

\section{PATIENTS AND METHODS}

Serial prekallikrein estimations were performed in four critically ill patients in an intensive care unit who were receiving appropriate supportive therapy. Patient details are shown in Table 1. Single prekallikrein estimations were performed in 15 patients attending the Accident and Emergency Department, Royal Infirmary, Edinburgh with varying degrees of trauma. Blood samples were taken immediately on arrival in the Department, prior to treatment. Trauma was graded according to the standard injury severity score (Baker et al., 1974). A normal range for plasma prekallikrein was established in 26 healthy adult control subjects.

Plasma prekallikrein estimations were performed by the method of Friberger et al., (1978); $9 \mathrm{ml}$ blood was taken into plastic tubes containing $1 \mathrm{ml} 0.1$ mol sodium citrate. Plasma was separated and stored at $-20^{\circ} \mathrm{C}$ until assayed. Plasma $(100 \mu \mathrm{l})$ was incubated at $37^{\circ} \mathrm{C}$ for $120 \mathrm{~s}$ with $800 \mu \mathrm{l}$ prekallikrein activator (Cephotest) to convert prekallikrein to active kallikrein. The synthetic tripeptide chromogenic substrate H-D-Pro-PheArg-pNA (S2302, Kabi Diagnostica, Stockholm, Sweden), for which plasma kallikrein is specific, was added to the incubation mixture $(100 \mu \mathrm{l})$; the reaction was terminated after a further $60 \mathrm{~s}$ incubation at $37^{\circ} \mathrm{C}$ by the addition of $100 \mu 150 \%$ acetic acid. The absorbance at $405 \mathrm{~nm}$ due to the pNA dye liberated from the substrate was measured by spectrophotometry. A standard pool of normal human plasma was prepared by mixing $3 \mathrm{ml}$ of citrated plasma from each of 12 healthy adult subjects. Dilutions of this standard pool were used to prepare standard curves for each run of the assay; the absorbance for each sample was plotted on this standard curve and the prekallikrein concentration expressed as a percentage of the value for the standard pool. Statistical comparison between groups was performed by the Wilcoxon rank sum test; all results are expressed as mean \pm standard deviation. 


\section{RESULTS}

Plasma prekallikrein concentration in the 26 healthy controls was $104 \pm 23 \%$ of the standard pool value (mean $\pm \mathrm{SD}$ ). The results of serial observations in the four critically ill patients are shown in Fig. 2; initial, mean and lowest prekallikrein values are showre in Table 1. Comparing the mean values in this group with the control group, plasmo: prekallikrein was significantly lower than in the controls $(51 \pm 13 \%$, controls. $104 \pm 23 \%, p<0.01)$. In two patients prekallikrein values $30-80 \%$ of normal were observed over a five-day period; both patients subsequently recovered, when normaL prekallikrein values were found. In the other two patients the plasma prekallikrein; initially in the same range, fell to undetectable levels. Both patients at that timew experienced severe circulatory failure and one patient died (Fig. 2, Table 1).

Compared with controls the 15 trauma patients showed a significant increase in. plasma prekallikrein (controls $104 \pm 23 \%$, trauma patients $181 \pm 44 \%, p<0.05$ ) (Fig $\vec{\omega}$ 3). There was no correlation between plasma prekallikrein and the injury severity score్ (correlation coefficient $0 \cdot 02, \mathrm{p}>0 \cdot 1$ ).

\section{DISCUSSION}

The reduction in plasma prekallikrein in critically ill patients in intensive care is 8 keeping with previous findings in septicaemic shock both in experimental animas so (Neiss et al., 1968), and in man (O'Donnell et al., 1976; Mason et al., 1970). Two of dầi patients (J.M. and R.M.) were obviously infected, although we cannot with certaintys exclude sepsis in the others. A reduction in plasma prekallikrein could reflect decreasedo hepatic synthesis of prekallikrein, or alternatively, increased conversion of prekallikreinğ to kallikrein, which is then rapidly degraded. Decreased synthesis of prekallikrein is known to occur in severe hepatic dysfunction (O'Donnell et al., 1976), but none of ouro patients had markedly deranged liver function tests. In two of the patients, rapid falls in

Table 1 Details of critically ill patients in intensive care ( $P K=$ prekallikrein)

\begin{tabular}{|c|c|c|c|c|c|c|c|}
\hline \multirow[b]{2}{*}{ Patient } & \multirow[b]{2}{*}{ Age } & \multirow[b]{2}{*}{ Sex } & \multirow[b]{2}{*}{ Diagnosis } & \multicolumn{3}{|c|}{ PK (\% of standard) } & \multirow[b]{2}{*}{ Outcome } \\
\hline & & & & Initial & Mean & Lowest & \\
\hline J.M. & 45 & $\mathbf{M}$ & $\begin{array}{l}\text { necrotising } \\
\text { fasciitis }\end{array}$ & 68 & 67 & 37 & survived \\
\hline E.J. & 24 & F & $\begin{array}{l}\text { stab wound } \\
\text { of left } \\
\text { ventricle }\end{array}$ & 67 & 39 & $<5$ & survived \\
\hline A.K. & 67 & $M$ & $\begin{array}{l}\text { multiple } \\
\text { trauma, } \\
\text { flail chest }\end{array}$ & 84 & 42 & $<5$ & died \\
\hline R.M. & 54 & $\mathbf{M}$ & $\begin{array}{l}\text { perforated } \\
\text { gastric ulcer, } \\
\text { septicaemia }\end{array}$ & 65 & 56 & 38 & survived \\
\hline
\end{tabular}


Table 2 Injury severity score and plasma prekallikrein concentration in traumatised patients

\begin{tabular}{lcc}
\hline Patient & $\begin{array}{c}\text { Injury severity } \\
\text { score }\end{array}$ & $\begin{array}{c}\text { Prekallikrein } \\
\text { (\% standard) }\end{array}$ \\
\hline D.B. & 10 & 229 \\
D.M. & 14 & 234 \\
J.F. & 13 & 172 \\
B.W. & 29 & 203 \\
M.J. & 13 & 186 \\
J.M. & 29 & 174 \\
G.A. & 14 & 241 \\
J.H. & 17 & 64 \\
L.D. & 17 & 174 \\
N.C. & 9 & 166 \\
P.M. & 29 & 206 \\
C.M. & 21 & 175 \\
E.D. & 13 & 147 \\
A.Q. & 14 & 139 \\
F.A. & 13 & 204 \\
n=15 & $17 \pm 6.8$ & $181 \pm 44 \%$ \\
\hline
\end{tabular}

plasma prekallikrein occurred (Fig. 2), at a rate which could not be explained purely by a decreased rate of synthesis. The results therefore suggest that activation of the plasma kallikrein kinin system occurs in critically ill patients and that in some cases such activation can be rapid and complete. Kallikreins are thought to play an important role in the conversion of prerenin to renin (Sealey et al., 1978). Consumption of all the circulating prekallikrein might therefore inhibit subsequent activation of the reninangiotensin system and interfere with this important compensatory response to hypotension. It may therefore be relevant that following disappearance of prekallikrein from the circulation one of our patients died in irreversible circulatory failure. The kinins formed as a result of activation of the kallikrein kinin system, in addition to causing vasodilation, will increase micro-vascular permeability, increase leakage of protein from blood to the interstitium, and thereby cause a reduction in plasma volume (McFarlane et al., 1972). Indeed, the injection of either kallikrein or bradykinin into animals produces a state remarkably similar to septicaemic shock (Mills, 1979; McFarlane et al., 1972). The effects of kinins on micro-vascular permeability and the chemotactic properties of active kallikrein for neutrophils (Kaplan et al., 1971) might contribute to the subsequent development of the adult respiratory distress syndrome. It therefore seems likely that activation of the plasma kallikrein kinin system will adversely affect the outcome in severely ill patients. Currently available inhibitors of plasma kallikrein, such as aprotonin, are poorly specific and not completely effective (Sumida, 1979). More potent and specific inhibitors might prove to have beneficial effects in septic, shocked and critically ill patients.

The significance of the increased prekallikrein concentration in traumatized patients is unclear. The subjects were studied immediately on arrival in the emergency department and it seems unlikely that any alteration in hepatic synthesis could be 


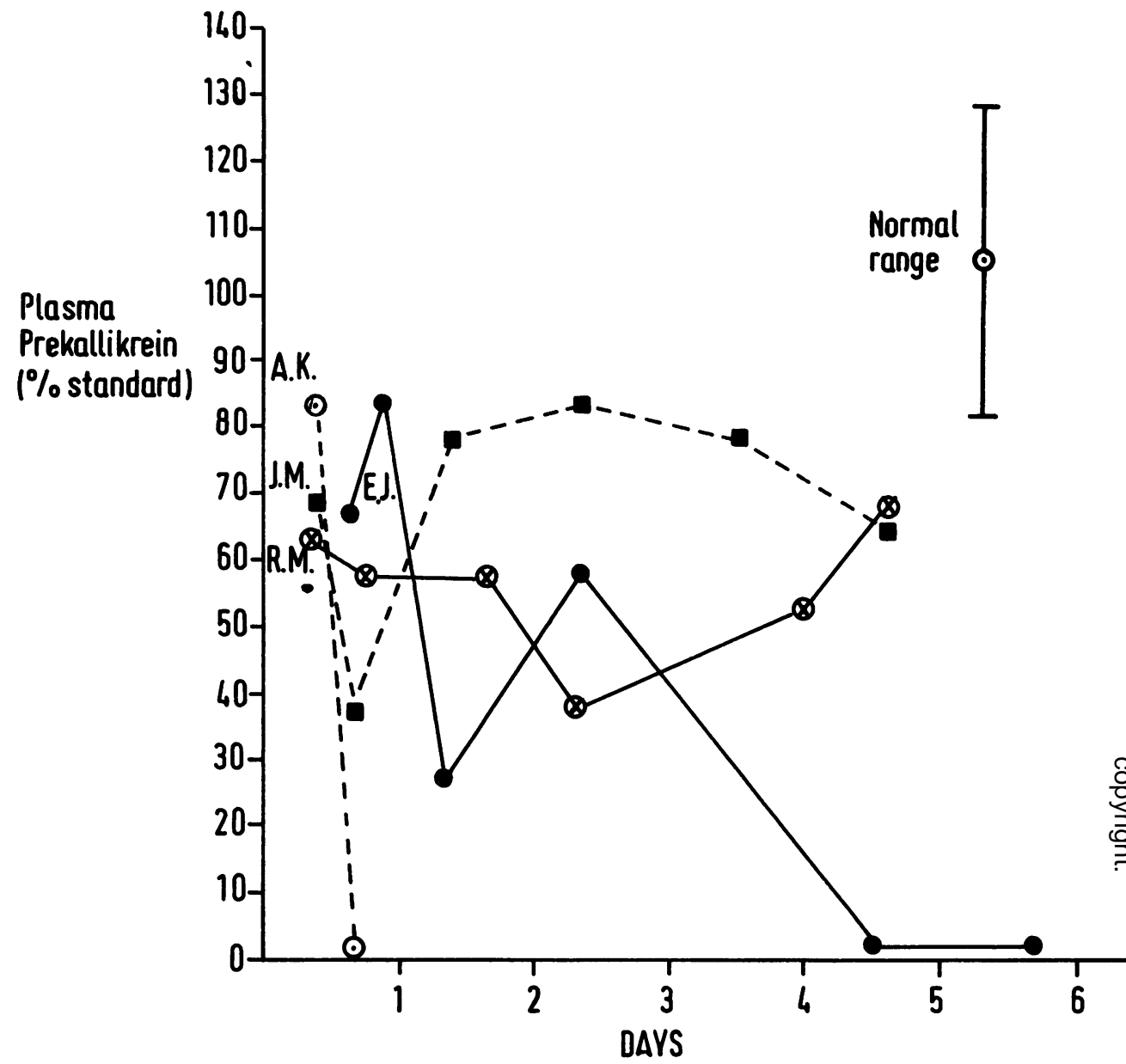

Fig. 2 Serial plasma prekallikrein concentrations in critically ill patients in an intensive care unit.

responsible. It seems more likely that prekallikrein is released into the circulation from an extravascular pool in response to trauma. Further studies are in progress to establish how much of this prekallikrein is converted to active kallikrein and to clarify how this newly observed phenomenon correlates with other aspects of the response to injury. 


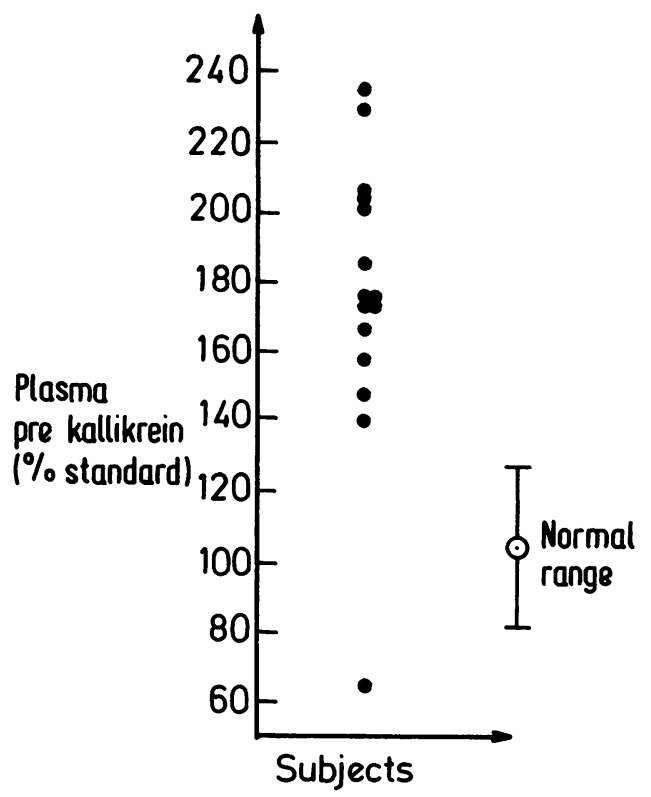

Fig. 3 Plasma prekallikrein concentrations in patients attending accident and emergency department with trauma.

\section{REFERENCES}

Abelous J-E. \& Bardier E. (1909) Les substances hypotensives de l'urine humaine normal. Comptes Rendus de la Societe de Biologie (Paris) 66, 511-12.

Baker S. P., O'Neil B., Hadden W. \& Long W. B. (1974) The injury severity score; a method for describing patients with multiple injuries and evaluating emergency care. fournal of Trauma 14, 187-96.

Friberger P., Eriksson E., Gustavsson S. \& Claeson G. (1978) Determination of prekallikrein in plasma by means of a chromogenic tripeptide substrate for plasma kallikrein. Advances in Experimental Medicine and Biology 120A, 67-82.

Kaplan A. P., Kay A. B. \& Austen K. F. (1971) Chemotactic activity of kallikrein for human neutrophils. Arthritis and Rheumatism 14, 392-3.

Kaplan A. P., Meier H. L. \& Mandle R. J. (1977) The role of Hageman factor, prekallikrein and high molecular weight kininogen in the generation of bradykinin and the initiation of coagulation and fibrinolysis. Monographs in Allergy 12, 120-30.

Kimball H. R., Melmon K. L. \& Wolff S. M. (1972) Endotoxin-induced kinin production in man. Proceedings of the Society of Experimental Medicine 139, 1078-82.

Levinsky N. G. (1979) The renal kallikrein-kinin system. Circulation Research 44, 441-51.

Mason J. W., Kleeberg U., Dolan P. \& Colman R. W. (1970) Plasma kallikrein and Hageman factor in gram negative bacteraemia. Annals of Internal Medicine 73, 545-51.

McFarlane N. A. A., Ward P. E. \& Mills I. H. (1972) Increased vascular permeability produced by kallikrein infusions and its enhancement by nephrectomy. Fournal of Physiology 231, 45-47.

Mills I. H. (1979) Kallikreins, kininogen and kinins in control of blood pressure. Nephron 23, 61-71.

Neiss A. A., Forsyth R. P., Williams H. W. \& Melmon K. L. (1968) Contribution of kinins to endotoxin shock in unanaesthetised rhesus monkeys. Circulation Research 22, 155-64.

O'Donnell T. F., Clowes G. H. A., Talamo K. C. \& Colman R. W. (1976) Kinin activation in the blood of patients with sepsis. Surgery, Gynaecology and Obstetrics 143, 539-45. 
Sealey J. E., Atlas S. A., Laragh J. H., Oza N. B. \& Ryan J. W. (1978) Human urinary kallikrein converts inactive to active renin and is a possible physiological activator of renin. Nature 275, 144-5.

Sumida S. (1979) Experimental studies on the effect of prophylactic proteinase inhibitor in shock. Advances in Experimental Medicine and Biology 120B, 395-401.

Webster M. E. \& Clark W. R. (1959) The significance of the callikrein-callidinogen-cinin system in shockAmerican fournal of Physiology 197, 406-12.

Received 4 May 1984; editorial comments to authors 11 May; accepted for publication 21 May 1984

\section{ACKNOWLEDGEMENTS}

We thank Dr K. Little for permission to study patients under his care, and Mrs Caroß McLaren for typing the manuscript. The study was approved by the Ethical Committee of the Royal Infirmary, Edinburgh. 